Research Article

\title{
Association of Dietary Intake with Nutritional Status of School-Going Children (5-10 years) in District Charsadda
}

\author{
Attaullah Jan ${ }^{1 *}$, Saleem Khan ${ }^{2}$, Iftikhar Alam ${ }^{1}$, Farzeen Khan ${ }^{3}$ and Muhammad Farooq ${ }^{4 *}$
}

${ }^{1}$ Human Nutrition and Dietetics, Department of Agriculture, Bacha Khan University, Charsadda, Khyber Pakbtunkhwa, Pakistan; ${ }^{2}$ Department of Human Nutrition, Faculty of Nutrition Sciences, the University of Agriculture, Peshawar, Khyber Pakhtunkhwa, Pakistan; ${ }^{3}$ Department of Community Health Sciences, Peshawar Medical and Dental College, Warsak Road Peshawar, Khyber Pakbtunkhwa, Pakistan; ${ }^{4}$ College of Food Science and Engineering, Northwest A and F University, Yangling, Shaanxi 712100, PR China.

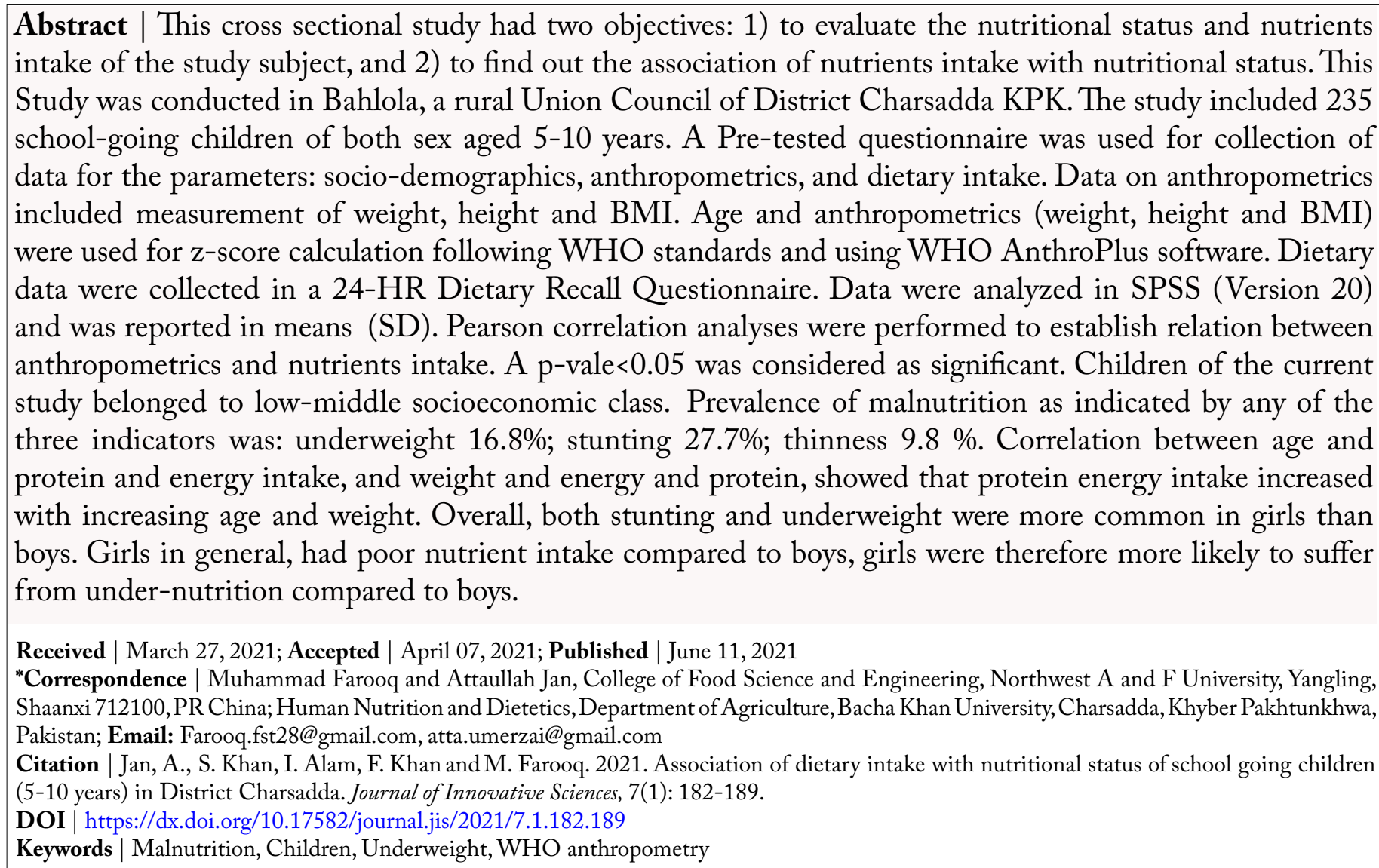

\section{Introduction}

Chool-going age is the active growing stage of Sindividual's life span (UNICEF, 2003). This stage of life is vital for physical growth and mental development. Balanced diet, both in terms of dietary diversity, amount and all essential nutrients intake is one of the important determinants of malnutrition in this age group (Ergin et al., 2007) While there may be differences in the prevalence and magnitude of malnutrition, children of school going age are considered a risk group for under-nutrition (Odunayo 
and Oyewole, 2006). Globally under nutrition is the single larger responsible cause for more than one-third of children deaths (Black et al.,2008) and worldwide it is the largest reason for $11 \%$ of the diseases. It is major common problem among low and lower-middle income countries (UNICEF, 2007).

Globally malnutrition in childhood is one of the major health problem which affecting both an individual and community level health status; In particular, childhood malnutrition has serious implications for health which causes serious nutritional problems in later stage of life. Studies have proved that in developing countries malnutrition affecting large number of children (Ergin et al., 2007). Under nutrition is the single larger responsible cause for more than one-third of children deaths (4), and worldwide it is the largest reason for $11 \%$ of the diseases. As per UNICEF report, under-nutrition contributes to the deaths of about 5.6 million children under five in the developing world each year (UNICEF, 2006). Nutritional status of children does not only reflect the socioeconomic status and social wellbeing of the family and community, but also reflects the academic out comes and cognitive and mental level efficiency of the health care system, and the influence of the surrounding environment as well as dietary intakes and habits. Research studies has previously indicated that under nutrition status, anemia and poor health in school age children are major causes of low intake of nutrients, high level of absenteeism, high dropout and academic performance below average of school going children (Bobonis et al., 2006).

Stunting, wasting, thinness, and underweight are the various forms of malnutrition in school-going children. Thinness refers to wasting which indicates acute malnutrition, and stunting, which results from long term nutritional deprivation (Black et al., 2008), are the major childhood nutritional concerns of Pakistan (Black et al., 2008). Malnutrition in school-going age children is a major common problem among low and under developed countries (UNICEF, 2007). Globally more than 200 million school-going age children will be stunted and underweight: while one billion of these children will be growing up with impaired physical and mental development by 2020 Trends in Child Mortality HIV/AIDS (UNICEF, 2007).

Pakistan is a developing country where malnutrition is widely spread among all ages, especially at the highest level in school age, according to the National Nutrition Survey (Bhutta et al., 2011) about 34\% of all children are underweight, nearly $44 \%$ are stunted, $15 \%$ are wasted and about one-third of these children are anemic. These are alarming figures when compared with international figures of malnutrition prevalence. Pakistan is a country of diverse sets of populations. There are substantial diversity in overall dietary patterns and nutritional behaviors. This fact may compromise the general applicability of national findings on nutritional status on local situation a fact also supported by many scholars, particularly, after the eighteenth amendments and the National Finance Award, 2010 (Zaidi et al., 2013). Given the volatile nature of nutritional behavior, life-style changes, and other contributing factors, we hypothesize that there might be possibly significant changes in the prevalence of malnutrition in school-going age children in a rural settings of Khyber Pakhtunkhwa (KPK). Thus, we design the study to trace malnutrition and assess intake practices in school going children in a rural Union Council of District Charsadda of KPK. The main purpose was to see whether and how much, if any, the prevalence rate of malnutrition in a rural setting deviates from that of the national findings. Therefore, this study was conducted to evaluate the nutritional status and Nutrients intake of the study subjects. Another objective of the study was to investigate the association of nutrients intake with nutritional status of the study subjects. The study is very important from the view point of looking at the local data of malnutrition instead of the national data for more robustness and better corrective measures.

\section{Materials and Methods}

The present cross-sectional study was carried out at District Charsadda Union Council Behlola in selected primary level Government and Private Schools for both genders (boys and girls). Union Council (UC) Behlola of District Charsadda comprises of total of 20 villages. At the time of the study, the total population of the UC was 27000 according to the National Census Report, 2017. The total number of children 5-10 years of age at this area was about 12000 . The study included 235 students, the study sample consist of $52.1 \%$ boys and $47.9 \%$ of girls.

Data of the study subject was collected for sociodemographic status, anthropometric and 24 hours dietary intake through asking question using WHO

Journal of Innovative Sciences

June 2021 | Volume 7 | Issue 1 | Page 183 
standard anthropometric tools. This information was recorded in pre-tested questionnaire. Data of sociodemographics, age and sex of the students, family size, and income level including nutrients intake was collected. Data regarding Parent's socio-economic status and educational background was also recorded through self-developed questionnaire. Data regarding Height, weight and age were recorded by using WHO established protocols. Weight was measured using Uni-scale to the nearest of $0.1 \mathrm{Kg}$ following WHO criteria for measuring weight. Height was measured to the nearest $0.1 \mathrm{~cm}$ with a wooden stadiometer, following WHO protocol for measuring height. Dates of Birth of the children were collected from School Attendance Withdrawal Register with the support of concern schools Head teacher. Data regarding Weight, Height and age was analyzed by WHO Anthro-Plus software. Dietary recall questionnaire was used to collect data of 24 hours nutrients intake. A briefed interview was held with the study subject regarding 24 hours intake with, teachers were involved to collect accurate information. The collected information was monitor during collection and was analyzed and updated where required.

All data were analyzed using SPSS software (version-20). Descriptive method of statistic applied for categorically variables, for continues variables t-test was used. Chi- square test was performed for the correlations and association of different variables. Anthropometric data was statistically analyzed by using WHO Anthro Plus and Nutrient intake calculator, respectively. Anthropometric. Data of the study subjects was analyzed by converting anthropometric data into anthropometric indices (Weight for age $Z$ score, Height for age $Z$ score and weight for age BMI $Z$ score) by using WHO Anthro Plus software. Data regarding Socio economic, age, gender, family size and family education status were also analyzed by IBMSPSS- statistical package (version-20)

\section{Results and Discussion}

A total of 235 school going children were selected for this study. Table 1 shows situation of current socio demographic of the study subjects. The mean age of boys was $8.01 \pm 1.08$ and girls were $7.9 \pm 1.53$. Majority of their parents (particularly mothers) were illiterate. Relatively a small number (23\%) of fathers of children were illiterate. A high number of the mothers of children (89.4\%) were housewife. More than half of the children $(52.3 \%)$ belonged to large family size $(\geq$ 6 persons). Most of the sample comprised of children of 7 years of age (33.1\%), followed by 8 years $(22.5 \%)$ and 10 years $(21.1 \%)$ of age.

\section{Table 1: Socio-demographic characteristics of the subjects.}

\begin{tabular}{ll}
\hline Characteristics & N(\%age) \\
\hline N (\%) & $123(52.1)$ \\
Boys & $112(47.9)$ \\
Girls & \\
Age (yrs.) & $8.01(1.08)$ \\
Boys & $7.91 .53)$ \\
Girls & \\
Father's education & $54(23.0 \%)$ \\
Illiterate & $58(24.7 \%)$ \\
Secondary & $29(12.3 \%)$ \\
Higher Secondary & $94(40.0 \%)$ \\
Graduate & \\
Mothers education & $102(43.4 \%)$ \\
Illiterate & $56(23.8 \%)$ \\
Secondary & $44(18.7 \%)$ \\
Higher Secondary & $33(14.0 \%)$ \\
Graduate & \\
Profession of father & $92(39.1 \%)$ \\
Govt. Servant & $49(20.9 \%)$ \\
Business & $76(32.3 \%)$ \\
Farmer & $18(7.7 \%)$ \\
Labor &
\end{tabular}

Table 2 shows mean (SD) weight and height of children according to age and sex.In each age category, boys were taller and heavier than girls. 
Table 2: Weight and height of children according to age and sex.

\begin{tabular}{llll}
\hline Age in years & Gender & Weight $(\mathbf{K g})$ & Height $(\mathbf{c m})$ \\
\hline \multirow{5}{*}{5} & Boys & $14.3(9.31)$ & $97.6(24.63)$ \\
& Girls & $25.8(8.21)$ & $131.2(27.21)$ \\
6 & Total & $40.12(17.52)$ & $228.83(51.84)$ \\
& Boys & $19.1(5.7)$ & $112.1(9.52)$ \\
& Girls & $25.0(4.60)$ & $119.43(13.68)$ \\
7 & Total & $45.1(10.3)$ & $231.53(23.2)$ \\
& Boys & $23.2(5.87)$ & $118.6(18.3)$ \\
8 & Girls & $23.64(6.52)$ & $112.17(11.87)$ \\
& Total & $46.84(12.39)$ & $230.77(30.17)$ \\
& Boys & $27.8(6.31)$ & $127.6(18.36)$ \\
9 & Girls & $26.11(7.67)$ & $120.61(9.44)$ \\
& Total & $53.91(13.98)$ & $248.21(27.8)$ \\
& Boys & $33.91(8.00)$ & $134.9(20.53)$ \\
\multirow{4}{*}{10} & Girls & $25.86(14.74)$ & $114.74(10.83)$ \\
& Total & $59.77(22.74)$ & $233.64(31.36)$ \\
& M & $31.3(8.58)$ & $131.41(22.38)$ \\
& F & $27.60(7.29)$ & $121.10(11.98)$ \\
& Total & $53.90(15.87)$ & $256.01(34.36)$ \\
\hline
\end{tabular}

Table 3 shows mean (SD) values of WAZ, HAZ and WHZ of children. As shown, mean values (SD) of WAZ, HAZ and WHZ of children were positive. Furthermore, boys had mean values of HAZ and WHZ greater than those for girls.

Table 3: Mean (Sd) values of (W.A.Z, H.A.Z and W.H.Z).

\begin{tabular}{lllll}
\hline \multirow{2}{*}{ Variables } & \multicolumn{3}{l}{ Mean (SD) } & p-value \\
\cline { 2 - 4 } & Cohort & Boys & Girls & \\
\hline WAZ & $0.292(1.74)$ & $0.41(1.60)$ & $0.15(1.88)$ & 0.250 \\
HAZ & $0.378(2.18)$ & $0.08(1.90)$ & $-0.88(2.36)$ & 0.000 \\
WHZ & $0.727(1.59)$ & $0.56(1.3)$ & $0.90(1.7)$ & 0.100 \\
\hline
\end{tabular}

Figure 1 illustrates WHO reference growth curves: As evident, $16.6 \%$ of the children were underweight (<-2SD WAZ score), $27.7 \%$ were stunted (<-2SD HAZ score), and $9.8 \%$ were thin (BMI z-score; $<-2 \mathrm{SD})$.

Table 4 shows a comparison of prevalence of undernutrition in boys and girls. A one- sample t-test between proportions was performed to determine whether there was a significant difference between the percent boys and girls being underweight, stunting, and thin. Percentage number of underweight boys (16.6\%) and girls (7.7\%) did not properly different as the t-statistic was not found significant at the 0.05 critical alpha level, $\mathrm{t}(236)=1.242, \mathrm{p}=0.412)$. However, there was a significant difference between the percent stunting and thin boys and girls. There were significantly more stunting girls as compared to boys $(27.7 \%$ vs. $10.2 \%)$ and significantly more wasted girls $(4.7 \%)$ than girls $(5.1 \%)$ ( $\mathrm{p}$, for all trends<0.05).

\section{Table 4: Nutritional status of children.}

\begin{tabular}{lllll}
\hline Variables & Combined & Boys & Girls & p-value \\
\hline Underweight & $39(16.6)$ & $18(7.7)$ & $21(8.9)$ & 0.412 \\
Stunted & $65(27.7)$ & $24(10.2)$ & $41(17.4)$ & 0.014 \\
Wasted & $23(9.8)$ & $11(4.7)$ & $12(5.1)$ & 0.005 \\
\hline
\end{tabular}

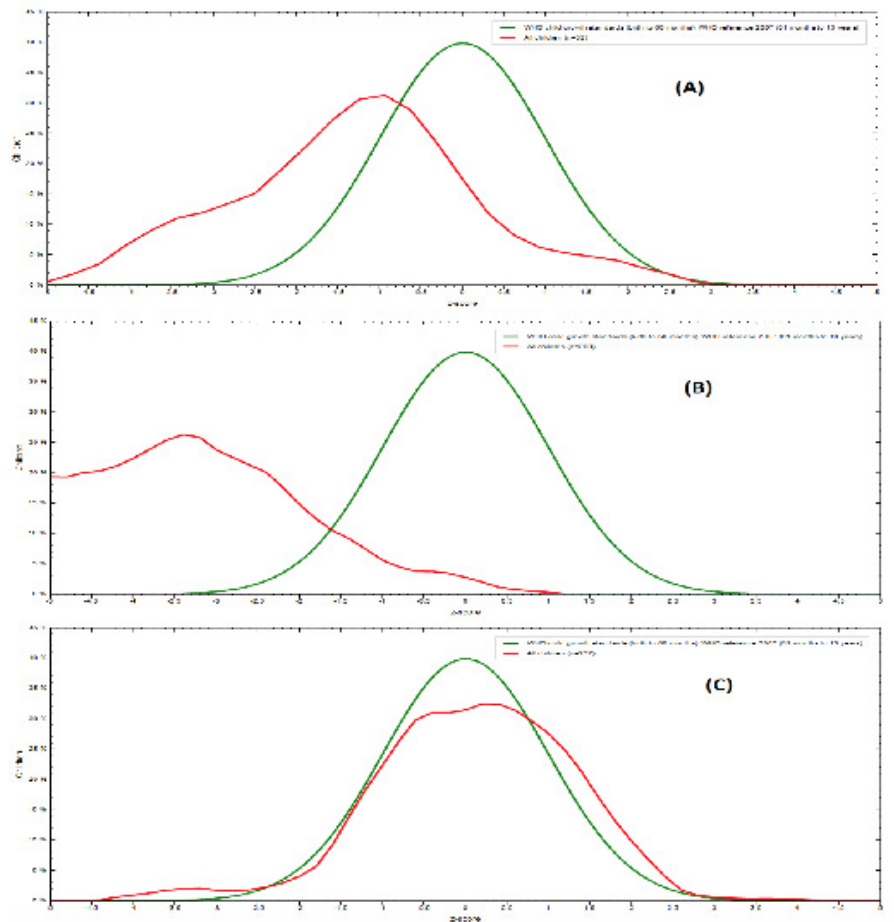

Figure 1:(A) Weight-for-age $z$-score in comparison to WHO child growth standards; (B) Height for age $z$-score in comparison to WHO child growth standards; (C) BMI for age $z$-score in comparison to WHO child growth standards.

Figure 2 shows a comparison of prevalence of underweight, stunting and wasting between boys and girls in two age groups. These further analyses were performed to see differences between percent boys and girls who were underweight, stunting and thin in each of the age groups 5-7 and 8-10 years. A onesample t-test between proportions was performed to determine whether there was a significant difference between the percent boys and girls being underweight, stunted, and thin in each of the age groups, 5-7 and 8-10 years. In the age group 5-7 years, percentage number of underweight boys and girls (11.6 each \%) 
did not significantly differ. However, such a difference was significant between boys and girls in the age group 8-10 years $(p=0.0315, t=1.814$ : Figure $1 \mathrm{~A})$. There were more stunted girls as compared to boys in both age groups i.e. $5-7$ years $(15.9 \%$ vs $11.55 \%)$ and 8-10 years (70.4 \% vs. $3.4 \%)$ (p-values, respectively, $>0.05$ and $<0.05)$. Similarly, there were significantly more wasted girls $(83.3 \%)$ as compared to boy (16.7 $\%)$ in the age group 5-7 years as well as in the age group 7.1-10 years (57.2 \% vs. $48.8 \%$ ) (p, for all trends $<0.05$ ).
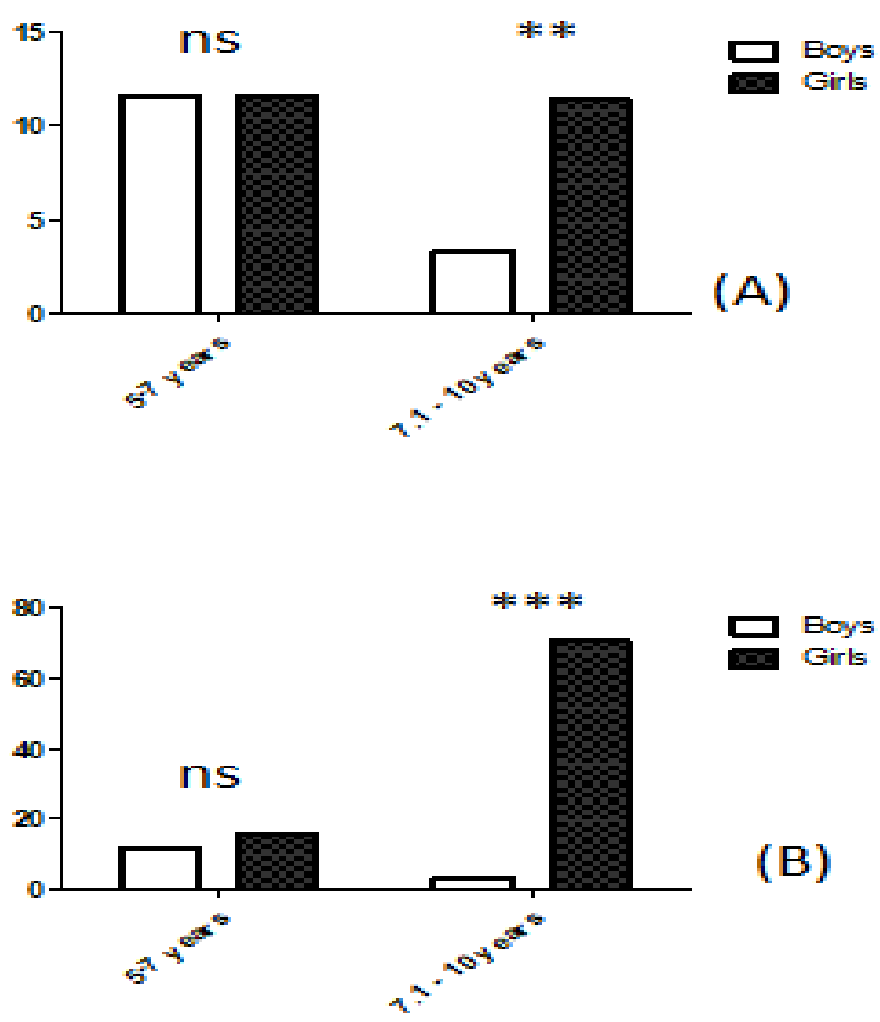

(B)

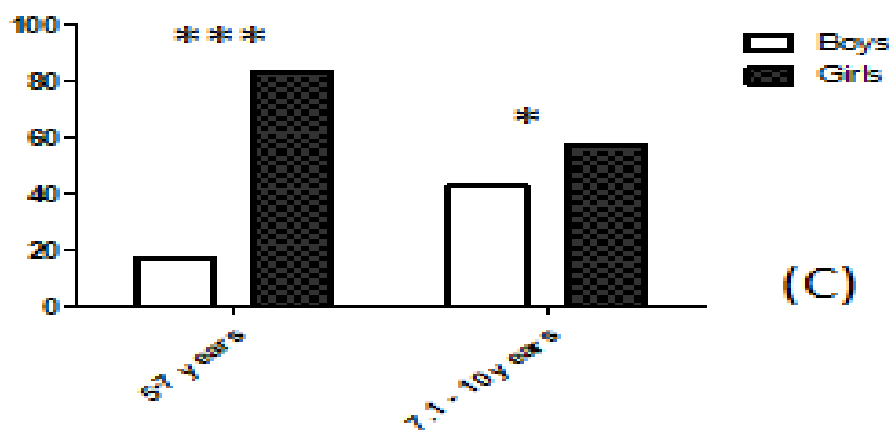

Figure 2: Prevalence of underweight (A), stunting (B) and thinness $(\mathrm{C})$ in boys vs girls in two age groups.

The present study was conducted on school going children at Union Council (UC) Behlola of district Charsadda. This cross sectional study subjects belonged to low- middle socioeconomic families. The burden of malnutrition, as indicated by any of the three indicators, was underweight $16.8 \%$; stunting is $27.7 \%$ and wasting is $9.8 \%$ (Khan et al., 2016).

The weight for Age Z- score (WAZ) and Height for Age Z- score distribution curves obtained from the study subjects were different than that of WHO standard (Figure 1). In WAZ curve, the mean value of children indicates to the left which means that most of the children in the population were affected as shown in Figure 2. In HAZ curve, the mean value of children was highly shifted to the left indicating that most of the children in the population, and not only those below a given cut-off, were affected as shown in Figure 1. The mean (SD) value of HAZ was 0.426 (2.94). In BAZ curve, the mean value of children was slightly shifted to the left as well as right indicating that only a few children in the population were affected as shown in Figure 1. The shift towards the right shows there were also some overweight and/ or obese children. The mean value (SD) of BAZ was 0.92 (1.49) (Bhutta et al., 2013).

In the current study, prevalence of overall under-nutrition (35.1\%) was lesser than previously reported (47\%) in a study by (12) in Peshawar, a nearby city to our study area. Also, another recent study reported prevalence of underweight (25.4\%) and stunting $(45.8 \%)$ in children in Faisalabad. The National Nutrition Survey of Pakistan, 2011 reported prevalence of underweight (31.5\%) and stunting (43.7\%) in children (Bhutta et al., 2013). In addition, the gender differences as a whole showed more girls being underweight (8.9 \% vs. 7.7; p=0.2415); significantly more girls compared to boys being stunted (17.4\% Vs. $10.2 \%$ ) and wasted (5.1\% Vs. 4,7\%) (p, for all trends< 0.05). Khan et al. (2016) showed thatthese gender based differences in the percent occurrence of under- nutrition reported in the current study were more prominent in the age group 8-10 years (Khan et al., 2016). The results of the present study are half reliable as compare to the findings of other South Asian countries studies previously conducted on the topic of gender difference in the malnutrition However, most of the previously performed studies resulted that more girls are being suffering from under-nutrition than boys. For example, Khan et al. (2016) reported the status of underweight in his study as 39\% (Mehmood et al., 2016). Mehmood et al. (2016) reported $32 \%$ children were malnourished, of these children 
stunted were 9\%, 11\% were underweight, and $4 \%$ were wasted. Ali et al. (2015) reported 9\% of children were stunted, $11 \%$ were underweight, and $4 \%$ were wasted. Afridi et al. (2014) reported that $14 \%$ underweight; $8 \%$ wasted; while $8 \%$ subjects were stunted. Ullah et al. (2014) reported results of 38\% male and $32 \%$ female children are malnourished. Gul and Kibria (2013) reported that $61 \%$ boys and $40 \%$ girls were resulted as malnourished. They further reported 30\% children as malnourished, $18 \%$ children were moderately, $10 \%$ were slightly and $2 \%$ were severely underweight. Mushtaq et al. (2011) reported 8\% and $10 \%$ children to be stunted and wasted, respectively. However, stunting and wasting was not significantly associated with child gender. Farid-ul-Hasnain (2010) and Khattak and Ali (2010) reported his results as $50 \%$ of pre-school children were suffering from malnutrition. Riaz et al. (2010) in his study on school age children reported $24 \%$ under-weight and $11 \%$ children stunted. Anwar and Awan (2003) reported that $46 \%$ of schools going kids were malnourished. Khuwaja et al. (2005) in his results showed that 16 percent are faced with stunted. Anwer et al. (2006) concluded in his study a 36\% stunned and 45\% underweight. Shah et al., (2003) reported a total of $26 \%$ wasted and $15 \%$ stunting stated $66 \%$ children were affected by malnutrition disorders in children of school going age.

Various factors may be responsible for the overall malnutrition that is gender base exploitation, differences in provision of adequate and proper diet (Laghari et al., 2015). This is a fact that malnutrition from infancy period have a serious consequences on child learning abilities in future stages of life (Asim and Nawaz, 2018). In the 7-10 years age groups of children in the current study, both stunting and underweight were more common in girls than boys. Although, growth spurt among the girls is seen as relatively earlier than the boys by approximately 2-3 years (Park, 2005). It is hypothesized that this difference in the growth status among boys and girls may be attributed to other factors such as nutrients intake, physical activity and due to infections (Batool et al., 2012). Additionally, as boys in general, has balance and proper intake of nutrient as that of girls, girls were found more malnourished as compared to boys, this is observed that boys might have more physical activities and hard work than that of girls, in the access to adequate food intake it is assume that boys having proper adequate nutrients consumptions than that of girls. Hence girls are to be on high risk for malnutrition than boys no easy access to adequate diet (Batool et al., 2012). Similarly, higher rate of malnutrition is observed among school-aged children of low- income and in developing countries such as India and Indonesia (Chhabra et al., 1996; Kulaga et al., 2010). There has been similar studies conducted at other countries such as Poland (Kulaga et al., 2010). Thus, while generally children below five years of age are considered to be a nutritionally vulnerable age group, older, school-age children may be as nutritionally vulnerable. Due to time limitations, unavailability of proper resource and small sample data size this study did not explore to find out the responsible factors for malnutrition. However, various studies have reported different socio-economic factors responsible for malnutrition. For example, children of the low income families were more like to be stunted and wasted as compared to high income families; diarrhea was strongly connected with underweight status of a child (Khan et al., 2016).

Mahmood et al. (2016) reported that malnutrition is directly proportional to the mother education status and with presence of family reported that low illiteracy large volume of family and starting of early weaning food during infancy in adequate breast feeding are the main and responsible factors for malnutrition. Achakzai and Khan (2016) recorded that sociodemographic characteristics, maternal health, and child health indicators are very closely associated with stunting and wasting. Khan et al. (2016) described that children in a nuclear family setup may have higher risk to be wasted and stunned. In addition, they added mother's education as a strong indicator for reducing the malnutrition burden in children. Moreover, girls were found to be more malnourished as compared to boys and children in the younger age group were found severely malnourished as compared to older age group. Ullah et al. (2014) found 38\% girls and $32 \%$ of boys malnourished in his conducted study for school age children. The authors reported that low awareness, education, lack of immunization, pregnancy in adolescences stage, and large family size are the common causes of malnutrition. Large family size, poor socio and economic status, mother's illiteracy, younger mothers, anemia and multipleparities were the major causes of child malnutrition. Batool et al.(2012) showed his study results as stunting was associated with birth interval less than 02 years. Khattak and Ali (2010) reported a vital relation of 
child malnutrition with income level, family size, and number of children in family. Ansari et al. reported lack of knowledge of child feeding; food insecurity and lack of child health facilities are the root cause of malnutrition in children (Baig-Ansari et al., 2006). Anwar et al. (2006) reported that $1 / 4^{\text {th }}$ of the children face with teeth problems and dental decay, scabies and multiple boils are the most common symptoms associated with malnutrition in children. Khuwaja et al. (2005) reported that those children whose fathers are farmers, servants and vendors were having more chances of being stunting in comparison to the children of landholders. Anwar and Awan (2003) stated that girls in rural areas are more underweight as compared to the boys. Mian et al. (2020) showed that poor status and big family size are responsible factors in child malnutrition. Shah et al. (2003) also mentioned that lack of awareness regarding proper nutrition education and unhealthy habits of children regarding proper nutrients intake are the key factors in child malnutrition in developing countries.

\section{Conclusions and Recommendations}

Under-nutrition was common in school going children, particularly it was in girls belonging to rural setting in District Charsadda.

\section{Novelty Statement}

This paper reported nutritional status of children from poorly represented community.

\section{Author's Contribution}

Attaullah Jan: Conceptualized, methodology, formal analysis and wrote-original draft.

Saleem Khan and Farzeen Khan: Helped in methodology section.

Iftikhar Alam: Helped in analysis.

Muhammad Farooq: Conceptualized, reviewed the manuscript and edited.

\section{Conflict of interest}

The authors have declared no conflict of interest.

\section{References}

Achakzai, P. and Khan, R., 2016. Nutritional status and associated factors among children less than five years of age in tehsil Zarghoon town,
District Quetta, Baluchistan. Journal of Ayub Medical College Abbottabad. 28(1): 146-151.

Afridi, M.F., Khushdil, A., Riaz, S. and Ehsan, A., 2014. Nutritional status of pre-school children. A cross-sectional study in Mingora, Swat. 28(3). Epub 2014-07- 25.

Ali, W., Ayub, A. and Hussain, H., 2015. Prevalence and associated risk factors of under nutrition among children aged 6 to 59 months in internally displaced persons of Jalozai Camp, District Nowshera, and Khyber Pakhtunkhwa. Journal of Ayub Medical College Abbottabad, 27(3): 556-559.

Anwar, H.N., Zafar, M.I. and Hussain, S., 2006. Health screening of primary school children. A case study of district Sargodha-Pakistan. Pak.J. Life Soc. Sci., 4: 40-47.

Anwer, I. and Awan, J.A., 2003. Nutritional status comparison of rural with urban school children in Faisalabad District, Pakistan. https://doi. org/10.22605/RRH130

Asim, M. and Nawaz, Y., 2018. Child malnutrition in Pakistan: Evidence from literature. Children, 5(5): 60. https://doi.org/10.3390/ children5050060

Baig-Ansari, N., Rahbar, M.H., Bhutta, Z.A. and Badruddin, S.H., 2006. Child's gender and household food insecurity are associated with stunting among young Pakistani children residing in urban squatter settlements. Food and Nutrition Bulletin, 27(2): 114-127.

Batool, S., Shaheen, A., Rehman, R., Qamar, S., Ahsan, Raza, S., Jabeen, R. et al. 2012. To assess the nutritional status of primary school children in an Urban school of Faisalabad. Pak. J. Med. Health Sci. A., 4: 160.

Bhutta, Z.A., Soofi, S.B., Zaidi, S.S.H. and Habib, A., 2011. Pakistan national nutrition survey, 2011.

Black, R.E., Allen, L.H., Bhutta, Z.A., Caulfield, L.E., De Onis, M., Ezzati, M., et al. 2008. Maternal and child undernutrition: Global and regional exposures and health consequences. The Lancet. 371(9608): 243-260. https://doi. org/10.1016/S0140-6736(07)61690-0

Bobonis, G.J., Miguel, E. and Puri-Sharma, C., 2006. Anemia and school participation. Journal of Human Resources, 41(4): 692-721. https:// doi.org/10.3368/jhr.XLI.4.692

Chhabra, P., Garg, S., Sharma, N. and Bansal, R., 1996. Health and nutritional status of boys aged 
6 to 12 years in a children observation home. Indian Journal of Public Health, 40(4): 126-129.

Ergin, F., Okyay, P., Atasoylu, G. and Beser, E., 2007. Nutritional status and risk factors of chronic malnutrition in children under five years of age in Aydin, a western city of Turkey. Turkish Journal of Pediatrics, 49(3): 283.

Farid-ul-Hasnain, S. and Sophie, R., 2010. Prevalence and risk factors for Stunting among children under 5 years: A community based study from Jhangara town, Dadu Sindh. J. Pak. Med. Assoc., 60(1): 41-44.

Gul, R. and Kibria, Z., 2013. Prevalence and predetermines of malnutrition in children under 3 years of age in the two rural communities of Peshawar. Khyber Medical University Journal, $5(4)$.

HIV/AIDS. JUNPo, UNICEF, 2010. Children and AIDS: Fifth Stocktaking Report, 2010: UNICEF; 2010.

Khan, J.R., Awan, N. and Misu, F., 2016. Determinants of anemia among 6-59 months aged children in Bangladesh: Evidence from nationally representative data. $B M C$ Pediatrics, 16(1): 3.

Khattak, M.K. and Ali, S., 2010. Malnutrition and associated risk factors in pre-school children (2-5 years) in District Swabi (NWFP)-Pakistan. Journal of Medical Sciences (Pakistan), 10(2): 3439. https://doi.org/10.3923/jms.2010.34.39

Khuwaja, S., Selwyn, B.J. and Shah, S.M., 2005. Prevalence and correlates of stunting among primary school children in rural areas of southern Pakistan. Journal of Tropical Pediatrics, 51(2): 72-77. https://doi.org/10.1093/tropej/ fmh067

Kulaga, Z., Litwin, M., Tkaczyk, M., Różdżyńska, A., Barwicka, K., Grajda, A., et al. 2010. The height-, weight-, and BMI for age of Polish school aged children and adolescents relative to international and local growth references. $B M C$ Public Health, 10(1): 109.

Laghari, Z.A., Soomro, A.M., Tunio, S.A., Lashari, K., Baloach, F.G., Baig, N.M., et al. 2015. Malnutrition among children under five years in district Sanghar, Sindh, Pakistan. Gomal Journal of Medical Sciences, 13(1).

Mehmood, Y., Ahad, B., Gul, R. and Khan, T.A., 2016. Nutritional status of children under 5 years of age in three tertiary care hospitals of Peshawar. Journal of Islamabad Medical and
Dental College, 5(2): 50-53.

Mian, R.M., Ali, M., Ferroni, P.A. and Underwood, P., 2020. The nutritional status of school aged children in an urban squatter settlement in Pakistan. Pakistan Journal of Nutrition, 1(3): 121-123.

Mushtaq, M.U., Gull, S., Abdullah, H.M., Shahid, U., Shad, M.A. and Akram, J., 2011. Waist circumference, waist-hip ratio and waistheight ratio percentiles and central obesity among Pakistani children aged five to twelve years. BMC Pediatrics, 11(1): 105. https://doi. org/10.1186/1471-2431-11-105

Odunayo, S.I. and Oyewole, A.O.,2006. Risk factors for malnutrition among rural Nigerian children. Asia Pacific Journal of Clinical Nutrition, 15(4).

Park, K., 2005. Park's textbook of preventive and social medicine. Preventive Medicine in Obstet, Paediatrics and Geriatrics.

Riaz, R., Sultana, A., Hameed, S., Tehseen, I. and Sabir, S.A., 2010. Nutritional status of school going children. J. Rawalpindi Med. Coll., 14: 51-54.

Shah, S.M., Selwyn, B.J., Luby, S., Merchant, A. and Bano, R., 2003. Prevalence and correlates of stunting among children in rural Pakistan. Pediatrics International, 45(1): 49-53. https:// doi.org/10.1046/j.1442-200X.2003.01652.x

Ullah, H., Ullah, B., Karim, S., Tariq, I., Khan, A., Mir, S., et al. 2014. Malnutrition amongst under-five years children in Swat, Pakistan: Prevalence and risk factors. Tropical Journal of Pharmaceutical Research, 13(8): 1367-1370.

UNICEF, 2003. The millennium development goals: They are about children. UNICEF; 2003.

UNICEF, 2006. Progress for children: A report card on nutrition. UNICEF; 2006.

UNICEF, 2007. The state of the world's children 2008: Child survival. UNICEF; 2007. https:// doi.org/10.1017/CBO9780511511271

Wahab, N., Paracha, P., Hussain, T. and Hameed, S., 1993. Prevalence of malnutrition in male school children in a rural area of district Peshawar: A study of demographic and socioeconomic characteristics. Pak. J. Med. Res., 32(3):192-196.

Zaidi, S., Bhutta, Z.A., Mistry, R., Nawaz, G., Hayat, N., Mohmand, S.K., et al. 2013. Nutrition political economy, Pakistan. Province Report: Sindh. 